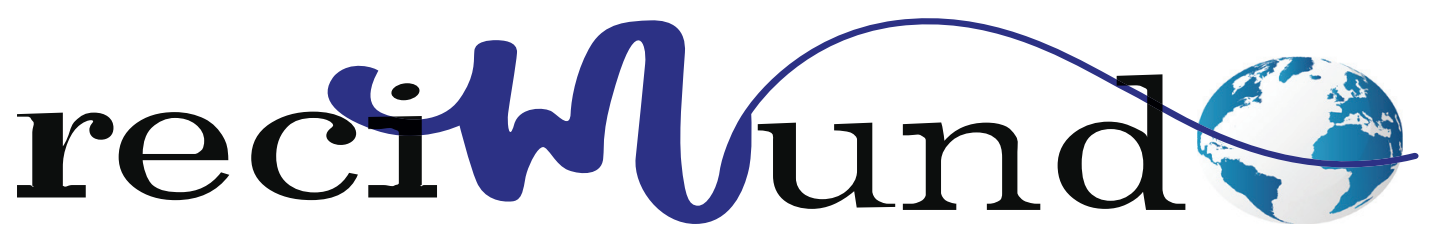

Revista Científica Mundo de la Investigación y el Conocimiento

DOI: 10.26820/recimundo/5.(4).oct.2021.96-111

URL: https://recimundo.com/index.php/es/article/view/1303

EDITORIAL: Saberes del Conocimiento

REVISTA: RECIMUNDO

ISSN: 2588-073X

TIPO DE INVESTIGACIÓN: Artículo de revisión

CÓDIGO UNESCO: 32 Ciencias Médicas

PAGINAS: 96-111

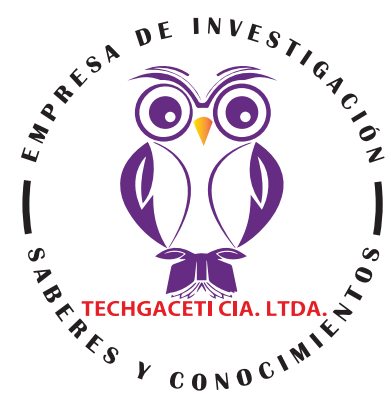

\title{
Diagnóstico y tratamiento de VIH en pacientes pediátricos
}

Diagnosis and treatment of HIV in pediatric patients

Diagnóstico e tratamento do HIV em pacientes pediátricos

Karolina de la Paz Arellano Salinas'; Jehan Franco Chalacan Araujo2; Carolina Misshell Narváez Álvarez;

Paulina Vanessa Mera Morales ${ }^{4}$

RECIBIDO: 02/09/2021 ACEPTADO: 20/09/2021 PUBLICADO: 30/10/2021

1. Médico General en Funciones Hospitalarias, Hospital Pediátrico Baca Ortiz; Quito, Ecuador; karitoarellano.md@gmail.com; (D) https://orcid.org/0000-0003-3041-846X

2. Bioquímico Clínico; Investigador Independiente; Quito, Ecuador; chalacanj@gmail.com; (iD https://orcid.org/0000-00033060-3999

3. Médica Cirujana; Investigador Independiente; Quito, Ecuador; caro93narvaez@gmail.com; (iD https://orcid.org/0000-00032354-2497

4. Médico Cirujano; Investigador Independiente; Ambato, Ecuador; vanessa.mera.27m@gmail.com; (iD https://orcid.org/0000-0002-9054-521X

\section{CORRESPONDENCIA}

Karolina de la Paz Arellano Salinas

karitoarellano.md@gmail.com

Quito, Ecuador

(c) RECIMUNDO; Editorial Saberes del Conocimiento, 2021 


\section{RESUMEN}

El virus de la inmunodeficiencia humana $(\mathrm{VIH})$ pertenece a la familia de los retrovirus, subfamilia lentivirus. Tienen una serie de características específicas que son determinantes en la compleja patogenia de la infección por el VIH. Con el fin de hacer una actualización del tema se presenta esta investigación exponiendo un resumen lógico de lo que se conoce hasta la fecha de la infección con VIH y el desarrollo del Sida en pacientes pediátricos. Es el caso de este trabajo, en donde se utilizan palabras claves como VIH, Síndrome de inmunodeficiencia adquirida (Sida), VIH en pacientes pediátricos, diagnóstico y tratamiento del sida en niños en los buscadores disponibles para publicaciones científicas como PUBMED, Scopus, Elsevier direccionados a través de Google académico que se encuentran los trabajos académicos en forma de libros, guías médicas, artículos científicos y se toman aquellos que no solo expongan información pertinente a la investigación , sino aquellos que también posean el índice de validación académica que permita exponer trabajos con validez científica en los resultados de la investigación. Dado el tema en cuestión, también se han consultado páginas oficiales de organizaciones mundiales que han dado seguimiento a la propagación del virus y las consecuencias experimentadas del mismo como la Organización Mundial de la Salud (OMS) y UNICEF a través de UNISIDA. La información disponible acerca de la prevención y manejo del VIH están a la mano de cualquier ser humano, en definitiva, para este flagelo hace falta mayor atención por parte de los organismos gubernamentales que tienen el poder para incentivar los mecanismos necesarios para alcanzar las metas propuestas por la OMS. Resulta sensible para la humanidad aceptar que un niño puede ser traído al mundo con los riesgos de padecer el SIDA, sin embargo los estudios y avances científicos hoy en día demuestran que es posible manejar satisfactoriamente las consecuencias por infección con VIH no solo en pacientes pediátricos sino en las madres seropositivas. Queda claro que en la prevención y de ser el caso el diagnóstico oportuno reside el éxito de los tratamientos en enfermedades agudas, el sida no es la excepción.

Palabras clave: $\mathrm{VIH}$, sida, diagnóstico, tratamiento, pacientes pediátricos.

\section{ABSTRACT}

The human immunodeficiency virus (HIV) belongs to the family of retroviruses, subfamily lentivirus. They have a series of specific characteristics that are decisive in the complex pathogenesis of HIV infection. In order to update the subject, this research is presented, presenting a logical summary of what is known to date about HIV infection and the development of AIDS in pediatric patients. This is the case of this work, where keywords such as HIV, acquired immunodeficiency syndrome (AIDS), HIV in pediatric patients, diagnosis and treatment of AIDS in children are used in the search engines available for scientific publications such as PUBMED, Scopus, Elseiver addressed Through academic Google, the academic works are found in the form of books, medical guides, scientific articles and those that not only expose information pertinent to the research are taken, but also those that also have the academic validation index that allows to expose works with scientific validity in the research results. Given the issue in question, official pages of world organizations that have monitored the spread of the virus and the consequences experienced have also been consulted, such as the World Health Organization (WHO) and UNICEF through UNISIDA. The information available about the prevention and management of HIV is at the hand of any human being, in short, this scourge requires greater attention from government agencies that have the power to encourage the necessary mechanisms to achieve the proposed goals. by WHO. It is sensible for humanity to accept that a child can be brought into the world with the risks of suffering from AIDS, however, studies and scientific advances today show that it is possible to satisfactorily manage the consequences of HIV infection not only in pediatric patients but also in HIV-positive mothers. It is clear that in the prevention and if it is the case the opportune diagnosis resides the success of the treatments in acute illnesses, the AIDS is not the exception.

Keywords: HIV, AIDS, diagnosis, treatment, pediatric patients

\section{RESUMO}

O vírus da imunodeficiência humana (HIV) pertence à família dos retrovírus, subfamília lentivírus. Apresentam uma série de características específicas que são decisivas na complexa patogênese da infecção pelo HIV. A fim de atualizar o assunto, esta pesquisa é apresentada, apresentando um resumo lógico do que se sabe até hoje sobre a infecção pelo HIV e o desenvolvimento da AIDS em pacientes pediátricos. É o caso deste trabalho, onde palavras-chave como HIV, síndrome da imunodeficiência adquirida (AIDS), HIV em pacientes pediátricos, diagnóstico e tratamento de AIDS em crianças são utilizadas nos buscadores de publicações científicas como PUBMED, Scopus, Elseiver abordadas Por meio do Google acadêmico, os trabalhos acadêmicos são encontrados na forma de livros, guias médicos, artigos científicos e são tomados aqueles que não apenas expõem informações pertinentes à pesquisa, mas também aqueles que possuem o índice de validação acadêmica que permite expor trabalhos com validade científica nos resultados da pesquisa. Diante do tema em questão, também foram consultadas páginas oficiais de organizações mundiais que monitoram a disseminação do vírus e as consequências vividas, como a Organização Mundial da Saúde (OMS) e o UNICEF, por meio da UNISIDA. As informações disponíveis sobre a prevenção e manejo do HIV estão ao alcance de qualquer ser humano, enfim, esse flagelo requer maior atenção dos órgãos governamentais que têm o poder de estimular os mecanismos necessários para o alcance dos objetivos propostos. por quem. É sensato para a humanidade aceitar que uma criança pode ser trazida ao mundo com os riscos de sofrer de AIDS, no entanto, estudos e avanços científicos hoje mostram que é possível gerenciar de forma satisfatória as consequências da infecção pelo HIV não só em pacientes pediátricos, mas também em mães seropositivas. É claro que na prevenção e se for o caso o diagnóstico oportuno reside no sucesso dos tratamentos em doenças agudas, a AIDS não é a exceção.

Palavras-chave: HIV, AIDS, diagnóstico, tratamento, pacientes pediátricos. 


\section{Introducción}

El virus de la inmunodeficiencia humana (VIH) pertenece a la familia de los retrovirus, subfamilia lentivirus. Ttienen una serie de características específicas que son determinantes en la compleja patogenia de la infección por el VIH:

- Gran diversidad genética (virus ARN) y genoma muy complejo (lentivirus).

- En su ciclo vital hay dos fases: virión infectante (ARN) y provirus (ADN). Esta fase intermedia de integración en el genoma huésped le permite prolongados períodos asintomáticos (latencia), a pesar de una viremia persistente.

- Se replica mediante un mecanismo inverso al habitual en los virus ARN. El papel fundamental lo juega un enzima llamada transcriptasa inversa (TI).

- Sus células huésped son los linfocitos CD4+, macrófagos, células nerviosas de la microglía y células dendríticas residentes en mucosas (células Langerhans). (Pascual Hernández \& Corral Arias, 2003, pág. 29).

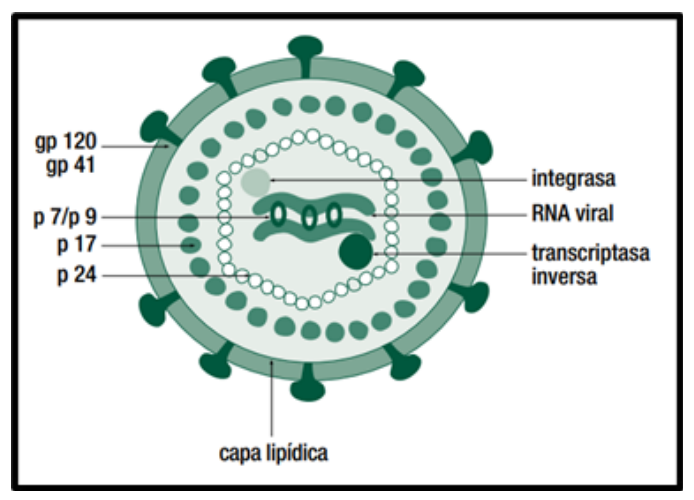

Figura 1. Estructura del VIH.

Fuente: (Pascual Hernández \& Corral Arias, 2003)

El VIH ataca el sistema inmunitario y debilita la defensa contra muchas infecciones y contra determinados tipos de cáncer. A medida que el virus destruye las células inmunitarias e impide el normal funciona- miento de la inmunidad, la persona infectada va cayendo gradualmente en una situación de inmunodeficiencia. La fase más avanzada de la infección por el VIH es el síndrome de inmunodeficiencia adquirida (sida), que en función de la persona puede tardar varios años en manifestarse si no se trata. Las personas con sida pueden contraer ciertos tipos de cáncer e infecciones oportunistas o presentar otras manifestaciones clínicas crónicas de gravedad. (Organización Mundial de la Salud, 2020)

EI SIDA es la expresión patológica última de la infección por el VIH. El virus destruye el sistema inmunológico lo que facilita la aparición de infecciones oportunistas que causan la muerte del enfermo. (Pascual Hernández \& Corral Arias, 2003)

Más de 2,8 millones de niños y adolescentes vivían con VIH en 2019, casi 9 de cada 10 en África subsahariana. (Organización Mundial de la Salud, 2020)

La mayor parte de las infecciones nuevas entre niños y adolescentes se dan en África Subsahariana, epicentro del VIH y el sida. Con el fin de romper el ciclo de nuevas infecciones y muertes, los niños, sus madres y los adolescentes deben hacerse pruebas de VIH y tener acceso al tratamiento. La principal prioridad de UNICEF es abordar los factores estructurales (como la pobreza, la falta de instrucción y la violencia) que exponen a las personas ( $y$, más concretamente, a las niñas y las mujeres jóvenes) al peligro de contraer el VIH. (UNICEF, 2021) Si bien se han registrado avances prometedores en la respuesta al VIH, los niños siguen sufriendo los efectos de la epidemia. Estas son algunas estadísticas sobre las infecciones de VIH entre niños y adolescentes en 2019:

- $\quad$ 2,8 millones de niños y adolescentes padecen $\mathrm{VIH}$.

- $\quad$ Solo un 53\% de los niños infectados reciben tratamiento para el $\mathrm{VIH}$, frente a un 
$85 \%$ de mujeres embarazadas que padecen $\mathrm{VIH}$.

- $\quad$ En ese año, se registraron alrededor de 320.000 nuevos casos en niños y adolescentes.

- $\quad 113.000$ niños y adolescentes murieron de causas relacionadas con el sida. (UNICEF, 2021)

Con el fin de hacer una actualización del tema se presenta esta investigación exponiendo un resumen lógico de lo que se conoce hasta la fecha de la infección con VIH y el desarrollo del Sida en pacientes pediátricos.

\section{Metodología}

Las revisiones bibliográficas representan en la actualidad el punto de partida para los avanzar en la investigación científica respecto a cualquier tema de interés. Esto debido a que la comunidad científica sigue creciendo y con ella una amplia exposición de los trabajos realizados a través del método científico.

El desarrollo de las TIC permite un empuje de las publicaciones científicas pues es posible hoy acceder a mucha información que sólo a través del conocimiento se pueden validar o desechar de acuerdo a la validación que la propia academia le brinda a la exposición de los trabajos.

Es el caso de este trabajo, en donde se utilizan palabras claves como VIH, Síndrome de inmunodeficiencia adquirida (Sida), VIH en pacientes pediátricos, diagnóstico y tratamiento del sida en niños en los buscadores disponibles para publicaciones científicas como PUBMED, Scopus, Elsevier direccionados a través de Google académico que se encuentran los trabajos académicos en forma de libros, guías médicas, artículos científicos y se toman aquellos que no solo expongan información pertinente a la investigación, sino aquellos que también posean el índice de validación académica que permita exponer trabajos con validez científica en los resultados de la investigación.

Dado el tema en cuestión, también se han consultado páginas oficiales de organizaciones mundiales que han dado seguimiento a la propagación del virus y las consecuencias experimentadas del mismo como la Organización Mundial de la Salud (OMS) y UNICEF a través de UNISIDA.

\section{Resultados}

La transmisión materno-infantil (TMI) del virus de la inmunodeficiencia humana (VIH) constituye la causa principal de transmisión del virus en menores de 15 años. Actualmente se conocen los mecanismos de la TMI, así como los protocolos de atención y los esquemas de tratamiento profiláctico para la gestante con VIH y el niño expuesto al virus.

Pese a que la atención en las embarazadas con $\mathrm{VIH}$ y la prevención de la TMI del virus se encuentran en la Norma Técnica 108-MINSA/DGSP «Prevención de la transmisión madre-niño del VIH y de la sífilis» del 2014, todavía existe una incidencia de transmisión de, aproximadamente, 4\% según la información obtenida de la Dirección de Prevención y Control del VIH, ITS y Hepatitis (DPVIH) y del Centro Nacional (peruano) de Epidemiología, Prevención y Control de Enfermedades (CDC MINSA), Io cual está alejado de la meta propuesta por la Organización Mundial de la Salud que es menor del 2\%. (Velásquez \& Espinola, 2020)

El VIH se puede transmitir de una madre seropositiva a su hijo durante el embarazo, el parto o la lactancia maternal (esto se llama transmisión maternoinfantil del VIH). La transmisión perinatal del VIH también se llama transmisión maternoinfantil del VIH. Algunos adolescentes, de 13 a 19 años de edad con el VIH en los Estados Unidos lo

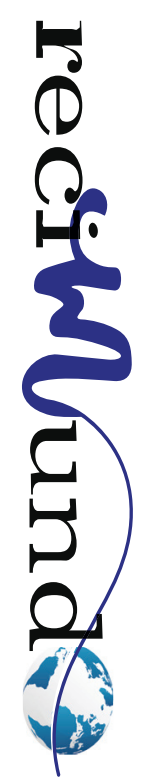


adquirieron cuando eran bebés a través de la transmisión maternoinfantil. Sin embargo, la mayoría de los jóvenes que contraen el VIH durante la adolescencia lo contraen por transmisión sexual. Muchos adolescentes con el VIH no saben que tienen el virus. (National Institutes of Health, 2021)

La tasa de mortalidad de los niños nacidos de madres seropositivas es más elevada que la de los niños con madres seronegativas y la incidencia de nacimientos prematuros y retraso del crecimiento intrauterino son también más elevadas, independientemente de si el lactante está infectado o no por VIH. Además, las mujeres que tienen una infección por VIH más avanzada no sólo corren un mayor riesgo de transmitir el VIH a sus hijos que las mujeres con un $\mathrm{VIH}$ menos avanzado, sino que sus hijos infectados tienen más posibilidades de morir antes de cumplir 6 meses de edad. La infección por VIH presenta una evolución más agresiva entre los lactantes y los niños que entre los adultos: un 30\% muere al año de vida, y un $50 \%$ a los dos años de vida, cuando no tienen acceso a medicamentos que pueden salvar las vidas, entre ellos la terapia antirretroviral e intervenciones preventivas como el cotrimoxazol (trimethoprim-sulfamethoxazole). (Organización Mundial de la Salud y UNICEF, 2009)

La mayoría de estas muertes de niños que tenían VIH se podrían haber evitado por medio de un diagnóstico temprano del $\mathrm{VIH}$ y una prestación a tiempo de atención y tratamiento eficaces para las enfermedades comunes en la infancia y las infecciones oportunistas, así como mediante la terapia antirretroviral. Los niños que sobreviven al primer año de vida tienen más posibilidades de morir de enfermedades comunes en la infancia. Las causas más frecuentes de mortalidad entre los lactantes y los niños que tienen $\mathrm{VIH}$ son las infecciones de las vías respiratorias, las enfermedades diarreicas y la tuberculosis, que por lo general se producen debido a graves factores de riesgo, entre ellos las infecciones oportunistas y la desnutrición, siendo la mortalidad por todas las causas mayor entre aquellos que tienen un bajo peso. Un deficiente estado nutricional hace que los niños con VIH sean más susceptibles a la morbilidad y la mortalidad, incluso cuando reciben terapia antirretroviral. (Organización Mundial de la Salud y UNICEF, 2009, pág. 11)

Tabla 1. Clasificación clínica de los Centros de Control de Enfermedad (CDC) 1994 de la infección por VIH.

\footnotetext{
Categoría N: asintomática

Niños que no presentan signos o síntomas atribuibles a la infección por VIH o aquellos que manifiestan solo una de las condiciones descritas en la categoría A

Categoría A: sintomatología leve

Niños que presentan dos o más de las condiciones que se describen a continuación, pero ninguna de las que se describen en las categorías B y C

- Linfadenopatía (>0,5 cm en más de dos localizaciones; bilateral=1 localización)

- Hepatomegalia

- Esplenomegalia

- Dermatitis

- Parotiditis

- Infecciones de vías respiratorias altas recurrentes o persistentes, sinusitis u otitis media

\section{Categoría B: sintomatología moderada}

Niños que presentan manifestaciones clínicas atribuibles a la infección por el VIH distintas a las enumeradas en las categorías A y

C. Como ejemplo, se describen a continuación algunas de las condiciones clínicas de la categoría B:

- Anemia $(<8 \mathrm{~g} / \mathrm{dL})$, neutropenia $\left(<1.000 / \mathrm{mm}^{3}\right)$ o trombocitopenia $\left(<100.000 / \mathrm{mm}^{3}\right)$ persistentes $>30$ días

- Meningitis bacteriana, neumonía o sepsis (episodio único)

- Candidiasis orofaringea (mugüet) persistente (>2 meses) en niños mayores de 6 meses

- Cardiomiopatía

- Infección por Citomegalovirus, con inicio durante el primer mes de vida
} 


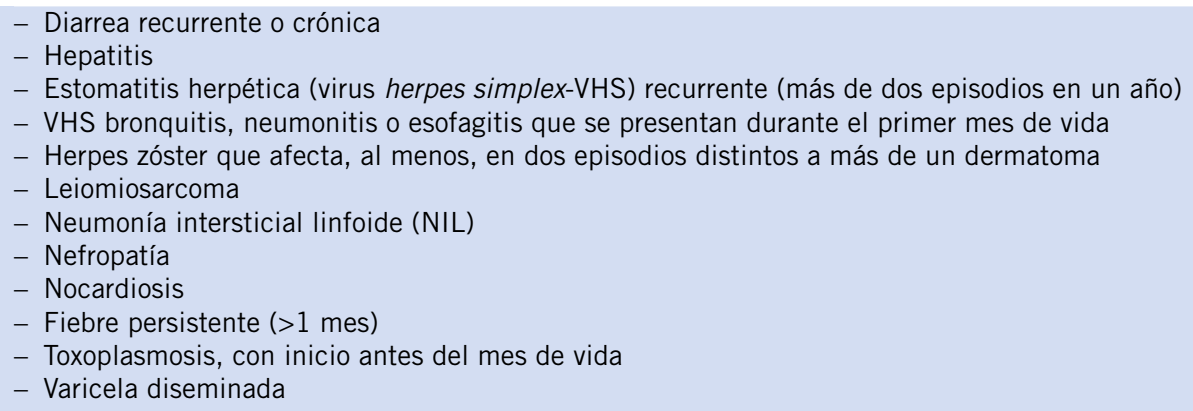

\section{Categoría C: sintomatología grave (SIDA)}

- Infecciones bacterianas graves, múltiples o recurrentes (cualquier combinación de, al menos, dos infecciones confirmadas con cultivo positivo en un periodo de 2 años) del siguiente tipo: septicemia, neumonía, meningitis, osteomielitis 0 artritis, 0 abscesos de órganos internos (excluyéndose: otitis, abscesos cutáneos o de mucosas, e infecciones relacionadas con catéteres)

- Candidiasis esofágica o pulmonar (bronquios, tráquea y pulmones)

- Coccidiomicosis diseminada (en una localización distinta o además de, en pulmón y ganglios linfáticos cervicales o hiliares)

- Criptoccocosis extrapulmonar

- Criptosporidiasis o isosporidiasis con diarrea persistente durante más de 1 mes

- Citomegalovirasis activa de inicio después del primer mes (en otra localización distinta a hígado, bazo o ganglios linfáticos)

- Encefalopatía (como mínimo uno de los siguientes hallazgos progresivos presentes durante, al menos, 2 meses, en ausencia de otras enfermedades concurrentes con la infección VIH que puedan explicar estas alteraciones): a) Pérdida o retraso en las adquisiciones propias de la edad o disminución de la capacidad intelectual, verificadas mediante la escala normal de desarrollo evolutivo o test neuropsicológicos. b) Alteración del crecimiento del cerebro o microcefalia adquirida, demostrada mediante la medición del perímetro craneal o atrofia cerebral, evidenciada mediante tomografía axial computerizada o resonancia nuclear magnética (se requieren alteraciones importantes en estas pruebas para el diagnóstico en niños menores de 2 años). c) Déficits motores simétricos puestos de manifiesto por dos o más de los siguientes hallazgos: paresia, reflejos patológicos, ataxia o alteración de la marcha

- Infección por herpes simplex con úlcera mucocutánea persistente durante más de 1 mes, o bronquitis, neumonitis o esofagitis de cualquier duración que se inicie después del mes de vida

- Histoplasmosis diseminada (en una localización distinta o además de, en pulmón y ganglios linfáticos cervicales o hiliares)

- Sarcoma de Kaposi

- Linfoma primario de SNC

- Linfoma de Burkitt o inmunoblástico o linfoma de células B o de fenotipo inmunológico desconocido

- Infección por Mycobacterium tuberculosis diseminada o extrapulmonar

- Infección por otras especies de Mycobacterium o especies no identificadas diseminadas (en una localización distinta o además de, en pulmón, piel y ganglios linfáticos cervicales o hiliares)

- Infección por Mycobacterium avium complex o Mycobacterium kansasii diseminada (en una localización distinta o además de, en pulmón, piel y ganglios linfáticos cervicales o hiliares)

- Neumonía por Pneumocystis jirovecci

- Leucoencefalopatía multifocal progresiva

- Bacteriemia por Salmonella (no tifoidea) recurrente

- Toxoplasmosis cerebral de inicio posterior al mes de vida

- Síndrome de emanciación en ausencia de otra enfermedad que coincida con la infección VIH, que justifique los siguientes hallazgos: A) pérdida mantenida de peso $>10 \%, \circ$ B) pérdida de peso durante el seguimiento, al menos, dos percentiles de las tablas en los niños de edad superior a 1 año, o $C$ ) peso por debajo del percentil 5 , en tablas de peso para la talla, en dos controles consecutivos separados, al menos, 30 días, además de: a) diarrea crónica (p. ej., 2 o más deposiciones por día durante, al menos, 30 días, o b) fiebre documentada (durante un período mínimo de 30 días, intermitente o mantenida)

Fuente: (Navarro Gómez, 2018)

\section{Diagnóstico de la infección VIH}

Se puede sospechar por la sintomatología que el niño presenta, así como por las alteraciones analíticas que el VIH produce. La confirmación de la infección se hará empleando distintas técnicas en función de la edad del niño. (Navarro Gómez, 2018)

Si este tiene más de 18 meses, se debe realizar una serología específica, pero si el niño es menor de 18 meses de edad, se deberán realizar test de diagnóstico virológico para detectar las partículas virales en la sangre. (Navarro Gómez, 2018)

Diagnóstico en el recién nacido expuesto a $\mathrm{VIH}$ : debe realizarse en las primeras 48 horas de vida, una prueba de RNA-VIH cualitativa mediante técnicas de biología molecular (carga viral). Esta técnica detecta el virus libre en plasma antes de que se integre en el linfocito, de modo que se ha utilizado como diagnóstico precoz de la 
P. V.

infección en el recién nacido, llegando a diagnosticar hasta el 93\% de los niños infectados en el momento del parto.

La técnica de detección de DNA-VIH por PCR, que identifica el VIH integrado en el linfocito, es una técnica diagnóstica que se ha usado mucho hasta la actualidad, pero puede no ser positiva inicialmente en los casos de infección en el parto. Para completar el estudio de diagnóstico neonatal, debe realizarse una segunda prueba de diagnóstico virológico mediante PCR a las 6-8 semanas de vida y, posteriormente, otra entre los 4-6 meses de edad. Toda prueba positiva debería confirmarse mediante una segunda prueba sin demorar el inicio del TAR. (Navarro Gómez, 2018)

La infección VIH se descarta mediante dos o más pruebas negativas de VIH realizadas en dos muestras de sangre independientes, después del mes de vida, y una de ellas más allá de los 4 meses. La infección puede excluirse razonablemente mediante pruebas serológicas específicas (Western blott), dos serologías negativas después de los 6 meses, separadas, al menos, un mes. La infección se descarta definitivamente con una serología negativa a los 18 meses. (Navarro Gómez, 2018)

Tabla 2. Riesgo de transmisión vertical del VIH según escenario materno.

\begin{tabular}{ll}
\hline RIESGO & ESCENARIO MATERNO \\
\hline BAJO & - Madre con terapia antirretroviral antes del nacimiento y carga viral indetectable cerca del nacimiento \\
ALTO & - Madre con terapia antirretroviral antes del nacimiento y carga viral detectable cerca del nacimiento \\
& - Madre con terapia antirretroviral solo durante el nacimiento \\
& - Madre con infección aguda durante el embarazo o lactancia
\end{tabular}

Fuente: (Hernández P., 2018)

\section{Intervenciones esenciales en materia de supervivencia infantil}

Las intervenciones de atención a los lactantes incluyen:

- Atención especializada en el momento de nacer;

- Cuidado termal;

- Cuidado higiénico del cordón umbilical;

- Una atención especial para los recién nacidos con bajo peso o prematuros:

- Iniciación temprana en la lactancia materna exclusiva (idealmente durante la primera hora); y una visita temprana postnatal (a ser posible durante las primeras 48 horas) (Organización Mundial de la Salud y UNICEF, 2009)
Las intervenciones en materia de prevención incluyen:

- Lactancia materna exclusiva hasta los 6 meses de edad;

- Alimentación complementaria segura desde los 6 meses de edad; una buena nutrición de la madre;

- Inmunización completa y a tiempo: BCG, hepatitis B, DPT (difteria, pertusis, tétanos), vacuna oral de la poliomielitis, sarampión y Haemophilus influenza tipo B;

- Suplementos de vitamina A;

- Seguimiento sistemático del crecimiento y evaluación del desarrollo;

- Mejora en el agua, el saneamiento y la higiene; y

- Mosquiteros tratados con insecticida. 
Las intervenciones en materia de tratamiento incluyen:

- Terapia de rehidratación oral para la diarrea;

- Búsqueda rápida de atención;

- Zinc para reducir las muertes debidas a la diarrea y la neumonía;

- Rápido tratamiento con antibióticos para la neumonía y la disentería;

- Rápido tratamiento contra el paludismo; y

- Gestión de la desnutrición grave (Organización Mundial de la Salud y UNICEF, 2009)

\section{Intervenciones esenciales para los lac- tantes y los niños que están expuestos al VIH o que lo tienen}

Además, las siguientes intervenciones son necesarias para los niños que están expuestos al VIH o que lo tienen:

- Profilaxis antirretroviral para las madres y los recién nacidos;

- Evaluación clínica temprana y sistemática;

- Pruebas de detección del VIH iniciadas por el proveedor, incluidas las pruebas de laboratorio para la detección del VIH en los recién nacidos;

- Orientación y apoyo para mejorar la nutrición y la alimentación de los recién nacidos y los niños de corta edad;

- Tratamiento preventivo con cotrimoxazol;

- Pruebas, prevención (incluida la profilaxis con isoniazida) y gestión de la TB;

- Terapia antirretroviral temprana;

- Apoyo a la adherencia al tratamiento;

- Seguimiento clínico y de laboratorio sistemático;

- Apoyo psicosocial; y

- Atención, tratamiento y apoyo a los miembros de su familia (Organización Mundial de la Salud y UNICEF, 2009, pág. 16)

\section{Intervenciones de pruebas del VIH}

1. Todos los niños expuestos al VIH deben ser sometidos a una prueba virológica temprana a las 4 a 6 semanas de edad. Debe asumirse que los lactantes que den positivo a la infección por VIH están infectados y comenzar la terapia antirretroviral.

2. Para todos los lactantes y niños donde el VIH es posible, se sospecha que existe o se reconoce que hay una exposición al $\mathrm{VIH}$, debe recomendarse la administración de pruebas de detección del VIH iniciadas por el proveedor y adecuadas para la edad.

3. Si no hay pruebas virológicas disponibles, entonces los lactantes de quienes se sospeche que estén infectados por el VIH o sean seropositivos y no se encuentren bien, con signos y síntomas que sugieran la presencia del $\mathrm{VIH}$, deben tratarse como si la infección por $\mathrm{VIH}$ fuese la causa. Hay que llevar a cabo pruebas de CD4, cuando estén disponibles, para evaluar la inmunodeficiencia y facilitar el reconocimiento de una presunta enfermedad grave por VIH que exija la administración inmediata de terapia antirretroviral.

4. Se debe recomendar la prueba del VIH a todos los miembros de la familia de los lactantes o los niños que se sabe que hayan estado expuestos al $\mathrm{VIH} \mathrm{O}$ estén infectados con el virus.

5. A los lactantes y los niños que pudieran sufrir TB se les debe administrar una prueba del $\mathrm{VIH}$.

6. Si la prueba de los anticuerpos del VIH es negativa en un niño menor de 18 meses que ya no recibe leche materna y quién no ha sido amamantado durante las últimas 6 semanas, se supone que el niño no esté infectado, y solamente se sugiere llevar a cabo una prueba virológica si los síntomas clínicos o los acontecimientos posteriores sugieren una infección por $\mathrm{VIH}$.

7. Se recomienda llevar a cabo una prue-

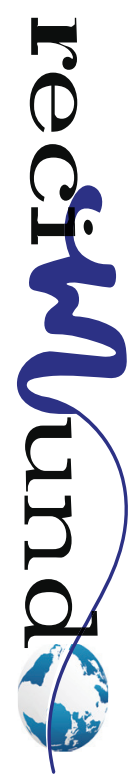


ARELLANO SALINAS, K. DE LA P., CHALACAN ARAUJO, J. F., NARVÁEZ ÁlVAREZ, C. M., \& MERA MORALES, P. V.

ba confirmatoria de los anticuerpos del $\mathrm{VIH}$ a los 18 meses para todos los niños expuestos al VIH (Organización Mundial de la Salud y UNICEF, 2009)

\section{Esquemas ARVs (antiretrovirales) reco- mendados}

La indicación de un esquema de terapia antirretroviral (TARV) inicial óptimo en niños y adolescentes, define su evolución a futu- ro en relación con la supresión de la replicación viral, en evitar o restaurar la función inmunológica y clínicamente en impedir la repercusión del VIH en el sistema neurológico, en preservar el desarrollo de los lactantes y en evitar la transmisión del virus en adolescentes. Estos factores condicionan que el tratamiento de inicio en la edad pediátrica debe estar ajustado a la edad, ofreciendo disponibilidad de los mejores esquemas según la evidencia. (Hernández P., 2018)

Tabla 3. Tratamiento retroviral en niños.

\begin{tabular}{|c|c|c|c|}
\hline Edad & Esquema Preferido & & \\
\hline Recién nacidos $<14$ días & $\begin{array}{l}2 \text { ITRN } \\
\text { Zidovudina+lamivudina }\end{array}$ & $\begin{array}{l}+ \\
+\end{array}$ & $\begin{array}{l}1 \text { ITRNN } \\
\text { Nevirapina }\end{array}$ \\
\hline Entre 14 días $\mathrm{y}<3$ años & $\begin{array}{l}\text { 2 ITRN } \\
\text { Abacavir } \dagger+\text { lamivudina } \\
\text { Zidovudina+lamivudina }\end{array}$ & $\begin{array}{l}+ \\
+\end{array}$ & $\begin{array}{l}1 \text { Inhibidor de proteasa/r } \\
\text { Lopinavir/ritonavir* }\end{array}$ \\
\hline Entre 2 años $y<3$ años & $\begin{array}{l}2 \text { ITRN } \\
\text { Abacavir } \dagger+\text { lamivudina } \\
\text { Zidovudina+lamivudina }\end{array}$ & $\begin{array}{l}+ \\
+\end{array}$ & $\begin{array}{l}1 \text { Inhibidor de Integrasa o } 1 \text { IP } \\
\text { Raltegravir*o Lopinavir/ritonavir }\end{array}$ \\
\hline \multirow[t]{3}{*}{$\geq 3$ años $y<6$ años } & $\begin{array}{l}\quad 2 \text { ITRN } \\
\text { Abacavir+lamivudina } \\
\text { Zidovudina+lamivudina }\end{array}$ & $\begin{array}{l}+ \\
+\end{array}$ & $\begin{array}{l}1 \text { Inhibidor de Proteasa/r } \\
\text { Atazanavir/ritonavir o Darunavir/ritonavir }\end{array}$ \\
\hline & $\begin{array}{l}\quad \mathbf{2} \text { ITRN } \\
\text { Abacavir+lamivudina } \\
\text { Zidovudina+lamivudina }\end{array}$ & $\begin{array}{l}+ \\
+\end{array}$ & $\begin{array}{l}1 \text { Inhibidor de Integrasa } \\
\text { Raltegravir }\end{array}$ \\
\hline & $\begin{array}{l}\quad 2 \text { ITRN } \\
\text { Abacavir+lamivudina } \\
\text { Zidovudina+lamivudina }\end{array}$ & $\begin{array}{l}+ \\
+\end{array}$ & $\begin{array}{l}1 \text { ITRNN } \\
\text { Efavirenz }\end{array}$ \\
\hline \multirow[t]{2}{*}{$\geq 6$ años $y<12$ años } & $\begin{array}{l}\quad \mathbf{2} \text { ITRN } \\
\text { Abacavir+lamivudina } \\
\text { Zidovudina+lamivudina }\end{array}$ & $\begin{array}{l}+ \\
+\end{array}$ & $\begin{array}{l}1 \text { Inhibidor de Proteasa/r } \\
\text { Atazanavir/ritonavir }\end{array}$ \\
\hline & $\begin{array}{l}\text { 2 ITRN } \\
\text { Abacavir } \dagger+\text { lamivudina } \\
\text { Zidovudina+lamivudina }\end{array}$ & $\begin{array}{l}+ \\
+\end{array}$ & $\begin{array}{l}1 \text { Inhibidor de Integrasa } \\
\text { Dolutegravir }\end{array}$ \\
\hline \multirow[t]{3}{*}{$\begin{array}{l}\geq 12 \text { años y Tanner } 1 \text { o } 2 \ddagger \\
\text { (o sin caracteres de maduración } \\
\text { sexual) }\end{array}$} & $\begin{array}{l}\mathbf{2} \text { ITRN } \\
\text { Abacavir/3TC o FTC } \\
\text { Tenofovir/FTC o 3TC }\end{array}$ & $\begin{array}{l}+ \\
+ \\
+\end{array}$ & $\begin{array}{l}1 \text { Inhibidor de Integrasa } \\
\text { Dolutegravir } \\
\text { Elvitegravir/COBI }\end{array}$ \\
\hline & $\begin{array}{l}\text { 2 ITRN } \\
\text { Abacavir/3TC o FTC } \\
\text { Tenofovir/FTC o 3TC }\end{array}$ & $\begin{array}{l}+ \\
+ \\
+\end{array}$ & $\begin{array}{l}1 \text { Inhibidor de proteasa/r } \\
\text { Atazanavir/ritonavir } \\
\text { Darunavir/ritonavir }\end{array}$ \\
\hline & $\begin{array}{c}2 \text { ITRN } \\
\text { Tenofovir/FTC o 3TC } \\
\text { Abacavir/3TC o FTC }\end{array}$ & $\begin{array}{l}+ \\
+\end{array}$ & $\begin{array}{l}1 \text { ITRNN } \\
\text { EFV }\end{array}$ \\
\hline
\end{tabular}

† Abacavir puede indicarse a partir de los 3 meses

* LPV/r no debe ser administrado a neonatos antes de una edad de fecha de última menstruación de 42 semanas y/o una edad postnatal de por lo menos 14 días. La nevirapina no se coloca como tratamiento de inicio dado inferioridad en respuesta virológica en comparación con LPV/RTV.

Fuente: (Hernández P., 2018) 
En vista de que se han presentado situaciones de desabastecimiento prolongado o interrupciones no programadas de ARVs, se han diseñado y discutido en Venezuela dichas recomendaciones en conjunto con representantes del Programa Conjunto de las Naciones Unidas para el VIH/Sida (ONUSIDA), la Organización Panamericana de la Salud (OPS), Programa Nacional de SIDA/ITS (PNSIDA) del Ministerio del poder popular para la salud (MPPS) y Grupo SIDA de la Sociedad Venezolana de Infectología (SVI). Se presentan en la siguiente tabla, los esquemas de ARVs sugeridos (Hernández P., 2018)

Tabla 4. Reinicio de ARVs de primera línea en niños

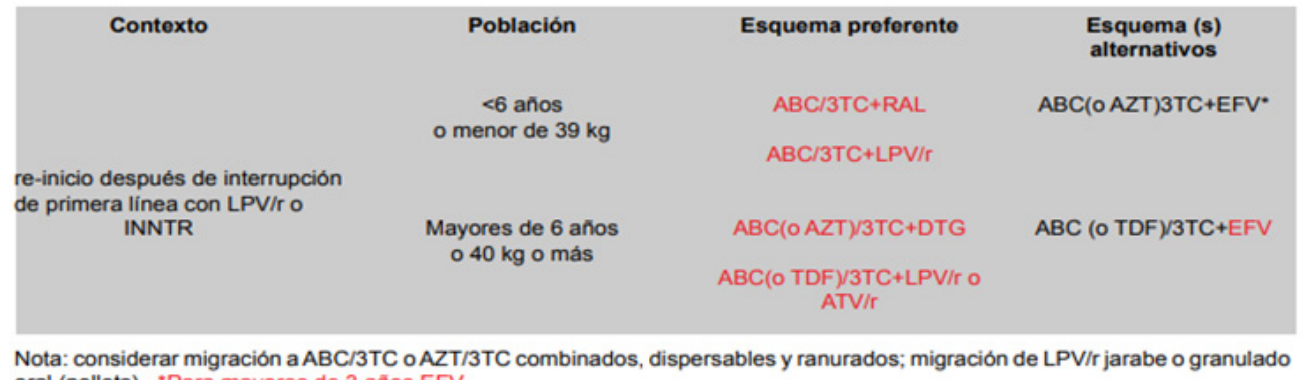
oral (pellets). "Para mayores de 3 años EFV.

Fuente: (Hernández P., 2018)

Tabla 5. Reinicio de ARVs de segunda línea en niños (B)

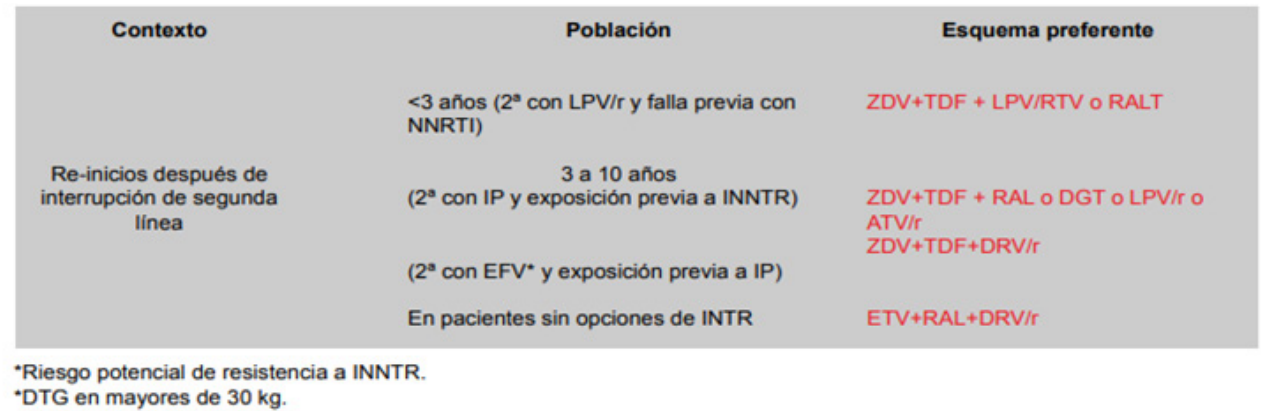

Fuente: (Hernández P., 2018)

\section{Cambio de TARV con CV indetectable y en fracaso terapéutico en niños y ado- lescentes}

Carga viral detectable Falla virológica está definida como una carga viral detectable y repetida $>200$ copias/ mm3 después de 6 meses de terapia ARV. Las causas de FV pueden ser multifactorial en los niños, pero la no adherencia representa un factor importante a evaluar, además de considerar que la dosificación sea la correcta, si existen interacciones medicamentosas que afecten su absorción y la sospecha de resistencia a los antirretrovirales. (Hernández P., 2018)
Falla virológica sin resistencia ARV identificada La persistencia de la viremia sin resistencia a los ARVs actuales obedece, usualmente, a la no adherencia, sin embargo, es importante descartar los factores antes descritos. Si se asegura una adecuada exposición a los ARV actuales, entonces la adherencia a los mismos debe conducir a la supresión virológica. Si se plantea investigar resistencia, es importante que el paciente reinicie el TARV actual y a las 4 semanas realizar test de resistencia (TR) si la CV permanece detectable. (Hernández P., 2018) 
Falla virológica con resistencia ARV identificada Cuando la decisión de cambiar el TARV es necesaria, se deben tomar en cuenta 2 o preferiblemente 3 drogas completamente activas de 2 clases de ARV diferentes, basados en el TR, historia ARV previa y la probabilidad de adherencia al nuevo tratamiento. Si el paciente falló a un esquema que contenía ITRNN, cambiar a un esquema que contenga IPs generalmente resulta efectivo. Si el fracaso es a un esquema que contenga IPs, emplear otro IP con mayor tolerancia y mayor potencia, como DRV/r, puede ser utilizado o cambiar a un INI puede ser efectivo. Los inhibidores de la integrasa (INI) están en la palestra actual en el tratamiento del paciente pediátrico con infección $\mathrm{VIH}$, siendo el más empleado Raltegravir, sin embargo, Dolutegravir se está postulando como una mejor alternativa dado a su administración de una vez al día, tabletas de pequeño tamaño y una barrera genética mayor, guardando actividad incluso en pacientes que han fallado al Raltegravir. (Hernández P., 2018)

Asimismo, esquemas que contengan INI, IP/r y Etravirina (Esquema TRIO) han sido efectivos en pacientes pediátricos extensamente resistentes. En el estudio NEVEREST 2 realizado en lactantes mayores a 3 años quienes estuvieron expuesto a Nevirapina y mantuvieron Lopinair/ ritonavir alcanzando la indetectabilidad, mantuvieron dicha supresión virológica cuando se cambió de Lopinavir/ritonavir a Efavirenz. Algunos estudios sugieren que el reemplazo de Lop/rit por un IP igual de potente (Darunavir o Atazanavir) o Inhibidor de Integrasa (Elvitegravir, Raltegravir, Dolutegravir) probablemente sería igual de efectivo, pero no ha sido estudiado directamente. La terapia dual o monoterapia con inhibidores de la proteasa (DRV/r, LOP/r o ATV/r) o INI como Dolutegravir que son estrategias que se plantean en pacientes adultos en algunos países, se muestran aún con resultados inconsistentes en la población pediátrica, razón por la cual no se recomienda. (Hernández P., 2018)

Las interacciones farmacológicas son sucesos que resultan en una alteración del efecto esperado de un fármaco debido a la utilización reciente o simultánea de otros fármacos, suplementos dietéticos, hierbas medicinales e incluso alimentos. (Castro, Campos, Figueroa, Yizmeyián, \& Piñero, 2021)

La terapia ARV ha permitido que los niños que acceden a ella tengan una expectativa y calidad de vida muy similar a la población general. Al ser medicamentos de uso poco frecuente en pediatría, resulta especial mente relevante dar a conocer las principales interacciones farmacológicas para evitar efectos indeseados al momento de prescribir otros fármacos en este grupo de pacientes. (Castro, Campos, Figueroa, Yizmeyián, \& Piñero, 2021)

En general, las reacciones adversas que involucran al sistema endocrino, incluyendo el síndrome de Cushing secundario a la administración de corticoides exógenos por un período prolongado, están entre las menos frecuentemente reportadas para fluticasona de administración intranasal o inhalada, esto debido a que este fármaco tiene una absorción sistémica menor al $2 \%$ cuando se administra por estas vías. Sin embargo, la coadministración con un antirretroviral como lopinavir/ritonavir, un inhibidor de proteasa, puede aumentar significativamente la absorción sistémica de fluticasona tras su administración intranasal o inhalada, siendo el mecanismo de esta interacción la inhibición del metabolismo de la fluticasona vía hepática e intestinal mediante el CYP450, isoenzima CYP3A4. La fluticasona es metabolizada por el sistema enzimático CYP450 3A4 y al coadministrarse con ritonavir, que actúa como inhibidor de este sistema enzimático, se produce en una acumulación del esteroide, supresión suprarrenal y síndrome de 
Cushing. Se deben considerar alternativas a la fluticasona, siempre que sea posible, si hay que usar ritonavir. (Castro, Campos, Figueroa, Yizmeyián, \& Piñero, 2021)

Como alternativas, pueden ser apropiados agentes menos potentes, menos lipofílicos y/o de acción más corta, tal como beclometasona, aun que probablemente la mayoría, si no todos los corticosteroides inhalados, pueden interactuar con ritona vir en alguna medida. Si no es posible prescindir de su uso se sugiere utilizar la dosis efectiva más baja posible del corticoide y ajustar según sea necesario, de acuerdo con la respuesta terapéutica, tolerancia del paciente y exámenes de laboratorio que evalúen la función del eje adrenal. Los pacientes deben ser monitorizados para detectar signos y síntomas de hipercortisolismo, además de realizar antropometría, ya que dentro de los hallazgos encontrados más precozmente se describe el rápido aumento de peso, pudiéndose evidenciar des de el primer mes de coadministración, como fue en el caso de nuestro paciente. Otra opción en pacientes con rinitis alérgica o asma bronquial es evaluar el uso de otros medicamentos, como podría ser antagonistas de receptor de leucotrienos, antihistamínicos, medidas no farmacológicas, entre otros. (Castro, Campos, Figueroa, Yizmeyián, \& Piñero, 2021)

Después de un uso prolongado de fluticasona con ritonavir, puede ser necesaria una reducción progresiva de la dosis de fluticasona si se quiere suspender indicación, ya que existe riesgo significativo de supresión de la función del eje adrenal, pudiendo ser necesario el uso de corticoides sistémicos en dosis de sustitución hasta la recuperación de la función del eje, tal y como sucedió en este paciente. (Castro, Campos, Figueroa, Yizmeyián, \& Piñero, 2021)

Los médicos que manejan patologías no VIH en estos niños, ya sea asma, alergias, patología neuropsiquiátrica, infecciones intercurrentes, arritmias u otras, deben verificar eventuales interacciones farmacológicas entre la terapia ARV y el tratamiento que van a indicar, siendo fundamental el apoyo y trabajo en conjunto con un Químico Farmacéutico clínico. (Castro, Campos, Figueroa, Yizmeyián, \& Piñero, 2021)

La incorporación del tratamiento antirretroviral de gran actividad (TARGA) mejoró la calidad y sobrevida de los niños con virus de inmunodeficiencia humana $(\mathrm{VIH})$, pasando de ser una enfermedad mortal a una infección crónica controlable con efectos metabólicos a corto y largo plazo. Sin embargo, la asociación entre TARGA y las posibles alteraciones antropométricas son poco conocidas en la población pediátrica. En un estudio retrospectivo, descriptivo y correlacional, a partir de historias clínicas de 56 niños de 0-12 años con $\mathrm{VIH}$ de transmisión vertical con TARGA, asistentes al Hospital Materno Neonatal de Córdoba, entre 1998-2014 se estudió en 3 controles médicos (primero, medio y último) y se evaluó peso para la edad (P/E), talla para la edad (T/E), índice de masa corporal (IMC), recuento de linfocitos T-CD4 (LT-CD4) y carga viral de VIH (CV-VIH). En cada control se analizaron variables antropométrica, inmunológica y virológica según TARGA administrado con inhibidores de proteasa (IP) y sin IP, a través del test de Wilcoxon (variables continuas) y test exacto de Fisher (variables categóricas) y se demostró no hubo diferencias estadísticamente significativas entre el TARGA suministrado y las variables antropométrica, inmunológica y virológica. Por lo tanto el estudio demostró la efectividad de la medicación a lo largo del tiempo en la población que no presentó morbi-mortalidad, mejoró su estado inmunológico, virológico y antropométrico con disminución de niños con desnutrición crónica. (Oberto, Asís, \& Defagó, 2018) 
El virus de la inmunodeficiencia humana (VIH) y el sistema nervioso central (SNC), El virus de la inmunodeficiencia humana (VIH) primordialmente linfotrópico, se caracteriza además, por tener un alto tropismo por el sistema nervioso central (SNC), al que puede infectar provocando distinto tipo de alteraciones neurológicas.

Los linfocitos, los monocitos y macrófagos son células diana del VIH; debido a esto, en el SNC la microglía es el tejido más afectado, ya que sus células son portadoras del receptor CD4 y del correceptor CCR5, los cuales permiten que el virus penetre en la célula. Esto lleva a que la microglía secrete citoquinas proinflamatorias que, a su vez, estimulan la síntesis de interleuquinas y prostaglandinas, iniciándose así una cascada de reacciones de tipo inflamatorio. La invasión prematura del SNC afecta el desarrollo cerebral del feto y el niño y resulta en la complicación más común del SNC asociada al virus, la encefalopatía por VIH $(E V I H)$. Este término alude al compromiso primario del cerebro debido al propio retrovirus, en ausencia de otras enfermedades o comorbilidades.

Las alteraciones neurológicas causadas por el VIH en niños pueden ser primarias, directamente relacionadas con la acción del VIH sobre el SNC, o bien, secundarias al desarrollo de infecciones oportunistas, alteraciones metabólicas relacionadas con el VIH y efectos secundarios al tratamiento antirretroviral (TARV).

El VIH se caracteriza por un gran neurotropismo, que está en relación con la heterogeneidad del virus. El mecanismo por el cual invade el SNC puede variar de un niño a otro, dependiendo probablemente del estado de maduración cerebral y del progresivo agotamiento inmune asociado a la replicación viral.
En niños sin TARV, la carga viral alcanza niveles muy altos durante los dos primeros años de vida y no disminuye en forma rápida como en los adultos. El riesgo de desarrollar esta la EVIH se incrementa cuando la infección se presenta en edades tempranas y con altas cargas virales. Es importante el diagnóstico precoz de la misma, ya que la presencia de la encefalopatía en sí es un indicador de severidad y progresión de la enfermedad. Incluso, la tasa de mortalidad es superior en niños con EVIH, particularmente en aquellos que la hayan desarrollado tempranamente. (Fernández, y otros, 2021)

Otra característica observada durante la infección por VIH es la presencia de infecciones oportunistas asociadas con el grado de inmunosupresión. Tres infecciones por Cryptococcus neoformans y una por Toxoplasma gondii, responsables de las manifestaciones neurológicas, fueron observadas en la población estudiada por Fernández, María Eugenia (2021) y otros en su estudio "Alteraciones neurológicas y su asociación con el estado inmunovirológico en niños infectados con VIH: 20 años de experiencia" y asociadas a una disminución importante en los niveles porcentuales y absolutos de LT CD4+. Con respecto a la infección por toxoplasma, cabe destacar que la madre de la paciente, infectada con $\mathrm{VIH}$, tuvo un embarazo no controlado y desarrolló toxoplasmosis durante el mismo. A diferencia de estos pacientes en donde la asociación enfermedad oportunista y manifestación neurológica fue evidente, en otros pacientes estudiados, no siempre fue posible relacionar la presencia de alteración neurológica con el desarrollo de la infección por VIH.

Varios niños presentaron un cuadro neurológico como manifestación de sospecha de la infección por VIH, lo cual es indicativo de la variedad en las formas de presentación de esta infección viral. Esto implica la necesidad de un correcto diagnóstico 
diferencial frente a otros cuadros clínicos que presenten distintos tipos de manifestaciones neurológicas.

Distintos autores demostraron que la incidencia y prevalencia de EVIH y otras alteraciones neurológicas han disminuido luego de la introducción de las terapias antirretrovirales. También se comprobó que, una vez establecida la encefalopatía, el TARV puede detener su curso e incluso revertirla. Por lo tanto, la supresión de la carga viral y la reconstitución del sistema inmune podrían tener un efecto protector contra el desarrollo de estas alteraciones.7Relacionados directamente con el nivel de inmunosupresión, evaluados a través de los LT CD4+, se encuentran los niveles de virus circulante, asociados, a su vez, con la adherencia al tratamiento antirretroviral. Una característica común en todos los pacientes evaluados fue la falta de adherencia al tratamiento, factor que agrega vulnerabilidad y predispone a diferentes tipos de alteraciones, no sólo neurológicas. (Fernández, y otros, 2021)

En pediatría, a todas estas variables se les debe sumar el hecho de que los niños no son autosuficientes en relación con la administración de las drogas y esto condiciona enormemente la adherencia, dado que dependen de un tercero responsable que asegure la toma correspondiente. Otro factor influyente está relacionado con las presentaciones farmacéuticas parcialmente accesibles para la población pediátrica, lo que dificulta, junto con todo lo anteriormente descripto, la adherencia al tratamiento. (Fernández, y otros, 2021) A diferencia de otras enfermedades crónicas, la rápida replicación y mutación del $\mathrm{VIH}$ hace que se requieran grados muy elevados de adherencia ( $\geq 95 \%$ ) para lograr una supresión duradera de la carga viral. Paterson y colaboradores encontraron que la adherencia en grados menores que el $95 \%$ predijo, independientemente, la resistencia viral, los ingresos hospitalarios y las infecciones oportunistas. (Fernández, y otros, 2021)

Es importante destacar que el desarrollo del sistema nervioso en pacientes infectados con VIH podría verse comprometido no solo por la existencia de una noxa, sino por una variedad de factores agregados. Una mala calidad de alimentación, pobres condiciones habitacionales, la falta de estimulación temprana, el contexto sociocultural, entre otras, son variables condicionantes para el adecuado desarrollo del niño. Aquellos expuestos a cualquiera de estas situaciones, son más vulnerables y tienen mayor probabilidad de desarrollar alteraciones neurológicas o neurocognitivas. En más del $25 \%$ de los niños estudiados, la aparición de signos y síntomas neurológicos fue la primera manifestación clínica que llevó a la sospecha de infección por VIH. Estos pacientes perdieron oportunidades para el diagnóstico temprano y la implementación del tratamiento antirretroviral. En los demás, la presentación neurológica estuvo asociada a fallo virológico y, en su gran mayoría, acompañada con inmunosupresión severa debido a una adherencia subóptima a los antirretrovirales. La reconstitución del sistema inmune, inducida por la supresión de la carga viral, disminuiría considerablemente la predisposición al desarrollo de patología neurológica y las secuelas asociadas. (Fernández, y otros, 2021)

\section{Conclusiones}

El tratamiento y la prevención de niños y adolescentes son las dos áreas de trabajo de UNICEF para detener las infecciones por el VIH y las muertes por SIDA. Lograr avances sostenibles en este trabajo requiere un mayor compromiso, mejores políticas y más fondos a nivel mundial, regional y nacional. (UNICEF, 2021)

Las mujeres que padecen VIH deben tener acceso a servicios que les permitan sobre-

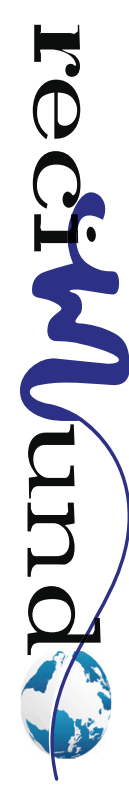


vivir y que frenen el contagio de $\mathrm{VIH}$ a sus bebés durante el embarazo, el parto o la lactancia materna. La asistencia continuada, las pruebas y la repetición de pruebas para las madres y sus bebés en esos periodos de tiempo pueden prevenir el contagio. Sin tratamiento, la mitad de los bebés que viven con el VIH morirán antes de cumplir dos años. Las pruebas tempranas y el tratamiento inmediato son la principal prioridad para los bebés expuestos al $\mathrm{VIH}$. Sin embargo, algunos laboratorios pueden tardar semanas en enviar a las madres los resultados del estado serológico respecto del VIH de sus bebés. UNICEF promueve una combinación de intervenciones biomédicas, conductuales y estructurales para reducir las infecciones de VIH entre los adolescentes. Estas soluciones innovadoras incluyen la profilaxis anterior a la exposición, el autodiagnóstico de VIH, servicios de protección en materia de $\mathrm{VIH}$ y la comunicación por móvil para mejorar el acceso al tratamiento y la atención. (UNICEF, 2021)

En los sitios en Internet de la OMS, UNICEF y Basic Support for Institutionalizing Child Survival (BASICS) se pueden conseguir recomendaciones más minuciosas sobre intervenciones decisivas en materia de supervivencia infantil, y la sección siguiente se centra en los lugares donde estas intervenciones exigen modificaciones para los niños que están expuestos al VIH o que lo tienen o donde se necesitan otras intervenciones debido a la presencia o exposición del VIH. En la página web de la OMS sobre salud y desarrollo del niño y el adolescente se puede obtener más información sobre el enfoque del ciclo vital en materia de supervivencia y desarrollo infantiles. (Organización Mundial de la Salud y UNICEF, 2009, pág. 16)

La información disponible acerca de la prevención y manejo del VIH están a la mano de cualquier ser humano, en definitiva, para este flagelo hace falta mayor atención por parte de los organismos gubernamentales que tienen el poder para incentivar los mecanismos necesarios para alcanzar las metas propuestas por la OMS.

Resulta sensible para la humanidad aceptar que un niño puede ser traído al mundo con los riesgos de padecer el SIDA, sin embargo los estudios y avances científicos hoy en día demuestran que es posible manejar satisfactoriamente las consecuencias por infección con VIH no solo en pacientes pediátricos sino en las madres seropositivas.

Queda claro que en la prevención y de ser el caso el diagnóstico oportuno reside el éxito de los tratamientos en enfermedades agudas, el sida no es la excepción.

\section{Bibliografía}

Castro, M., Campos, A., Figueroa, C., Yizmeyián, A., \& Piñero, C. (2021). Interacciones farmacológicas en niños con infección por $\mathrm{VIH}$ en tratamiento con antirretrovirales. Andes pediatrica, 92(3), http://dx. doi.org/10.32641/andespediatr.v92i3.3321.

Fernández, M. E., Prado, D., Sánchez, M. F., Balbaryski, J., Gaddi, E., \& Barboni, G. (mayo-agosto de 2021). Alteraciones neurológicas y su asociación con el estado inmunovirológico en niños infectados con VIH: 20 años de experiencia. Bioquimica y patología clínica, 85(2), 51-57.

Hernández P., M. J. (julio-diciembre de 2018). Consenso de VIH-2: tratamiento antirretroviral en niños, adolescentes y embarazadas. Boletín venezolano de infectología, 29(2), 77-84.

National Institutes of Health. (19 de agosto de 2021). El VIH y los niños y adolescentes. Obtenido de U.S. Department of Health and Human Services: https://hivinfo.nih.gov/es/understanding-hiv/factsheets/el-vih-y-los-ninos-y-adolescentes

Navarro Gómez, M. (octubre-noviembre de 2018). Infección VIH en Pediatría. Peditría Integral, XXII(7), 333-341.

Oberto, M., Asís, E., \& Defagó, M. (2 de octubre de 2018). Asociación entre estado nutricional, inmunológico y virológico con el tratamiento antirretroviral en niños infectados con virus de inmunodeficiencia humana, Córdoba. Investigación en Epidemiología y Salud Pública, JIC XIX, https://revistas.unc. 
edu.ar/index.php/med/article/view/21442.

Organización Mundial de la Salud. (30 de noviembre de 2020). VIH/Sida. Obtenido de WHO: https:// www.who.int/es/news-room/fact-sheets/detail/hivaids

Organización Mundial de la Salud y UNICEF. (2009). Ampliar la prevención, el diagnóstico y el tratamiento de los lactantes y los niños con el VIH: un marco de programación. Ginebra: Organización Mundial de la Salud.

Pascual Hernández, A., \& Corral Arias, J. (2003). El virus de la inmunodeficiencia humana. Inmunopatogenia. En D. Pachón, Jerónimo, E. Pujol de la Llave, \& A. Rivero Román, La Infección por el VIH. Guía práctica (págs. 29-36). España: Sociedad Andaluza de Enfermedades Infecciosas.
UNICEF. (octubre de 2021). VIH y Sida. Obtenido de UNICEF para cada infancia: https://www.unicef. org/es/vih

Velásquez, C., \& Espinola, M. (Octubre-diciembre de 2020). Caracterización de niños con VIH por transmisión materno-infantil atendidos en hospitales de Lima, Perú. Revista Peruana de Medicina Experimental y Salud Pública, 37(4), https://doi. org/10.17843/rpmesp.2020.374.4816.

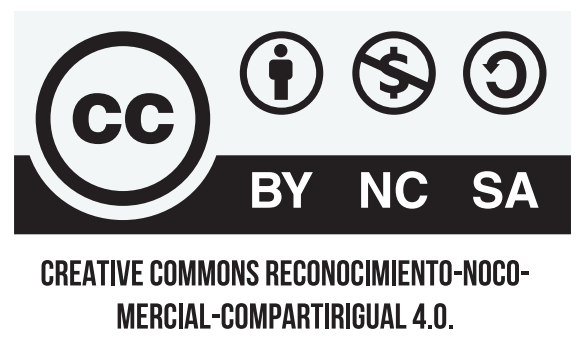

\section{CITAR ESTE ARTICULO:}

Arellano Salinas, K. de la P., Chalacan Araujo, J. F., Narváez Álvarez, C. M., \& Mera Morales, P. V. (2021). Diagnóstico y tratamiento de VIH en pacientes pediátricos. RECIMUNDO, 5(4), 96-111. https://doi.org/10.26820/recimundo/5.

(4).oct.2021.96-111 